Research article

\title{
Knowledge, attitudes and practices regarding gemstone therapeutics in a selected adult population in Pakistan Sidra Ishaque*1, Taimur Saleem ${ }^{1}$ and Waris Qidwai ${ }^{2}$
}

Address: ${ }^{1}$ Medical College, The Aga Khan University, Stadium Road, Karachi 74800, Pakistan and ${ }^{2}$ Department of Family Medicine, The Aga Khan University, Stadium Road, Karachi 74800, Pakistan

Email: Sidra Ishaque* - sidraishaque@gmail.com; Taimur Saleem - taimur@gmail.com; Waris Qidwai -waris.qidwai@aku.edu

* Corresponding author

Published: 26 August 2009

BMC Complementary and Alternative Medicine 2009, 9:32 doi:10.1 186/1472-6882-9-32

Received: 29 September 2008

Accepted: 26 August 2009

This article is available from: http://www.biomedcentral.com/l472-6882/9/32

(C) 2009 Ishaque et al; licensee BioMed Central Ltd.

This is an Open Access article distributed under the terms of the Creative Commons Attribution License (http://creativecommons.org/licenses/by/2.0), which permits unrestricted use, distribution, and reproduction in any medium, provided the original work is properly cited.

\begin{abstract}
Background: Gemstones have been in use as part of alternative and complementary medicine for years. However, our understanding of the perceived healing powers of gemstones is limited. An extensive literature search revealed that there is a dearth of validated information on this subject. This study was therefore undertaken to explore the various aspects of the knowledge, attitudes, and practices of the public towards gemstone therapeutics.
\end{abstract}

Methods: A survey was performed in the Community Health Centre of a tertiary care teaching hospital in Pakistan. Data collection was done via a face-to-face interview based on a structured, pre-tested questionnaire. Participants included all willing persons between 18-75 years of age approached prior to their appointments at the Community Health Centre.

Results: The survey response rate was $86 \%(400 / 465)$. More than half $(63 \%)$ of the study population was aware of the use of gemstone therapy. One hundred fifty-six individuals believed that gemstone use impacts health. Of this group, $39 \%$ believed that gemstone use increases physical strength. $62 \%$ believed that gemstone use is based on superstitious beliefs, whereas $28 \%$ opined that it is based on religious beliefs. $38 \%$ had used gemstones therapeutics formerly, while $24 \%$ were current users. Multiple logistic regression analysis revealed that age status and education status were significant $(p<0.05)$ independent predictors for both awareness of gemstone therapy and the belief that gemstone use impacts health. The elderly (aged 5I-6I) were 5.9-times more likely to believe that gemstones had an impact on health than the younger population (aged I8-28 years). (Adjusted Odd's Ratio $=5.9$ [95\% Confidence Interval $=2.9-11.9]$ ).

Conclusion: More than half of our sample population is aware of the use of the gemstones for their various effects. Willingness to use gemstones is associated with the beliefs about the impact of gemstone therapy on health. Friends and family seem to be the major role players influencing people's willingness to use gemstones. CAM modalities should be recognized and considered as an important therapeutic option. We feel that gemstone therapy is a relatively unexplored area and more studies should, therefore, be conducted to gather more validated information on the subject. 


\section{Background}

A gemstone is any mineral or petrified substance of beauty and durability that can be cut and polished for setting into a piece of jewelry or used for human adornment in other ways $[1,2]$. Gemstone therapy is most aptly described as a holistic and non-invasive therapy that involves wearing precious and semi-precious stones to improve physical and emotional health $[3,4]$.

Gemstones therapeutics is a part of complementary and alternative medicine (CAM). CAM refers to a group of medical and health systems, practices, disciplines and products that are not considered a part of conventional medicine $[5,6]$. According to estimates, more than $80 \%$ of the developing world utilizes CAM, and half of the developed world also uses CAM [7]. The 'raison d'etre' for using CAM includes dissatisfaction with conventional medicine [8] via failed treatments and high costs as well as high expense incurred from conventional medicinal treatments [9]. However, this does not imply that these are the only reasons why people would opt for CAM. Other reasons that have been cited for choosing CAM include more active role of the patient in health maintenance, emphasis of CAM on treating each individual as a whole, faulty patient-doctor communication and lack of a conventional treatment for the disease $[8,10]$. Moreover, utilization of CAM has been found to be predicted by anxiety, back problems, chronic pain and urinary tract dysfunction. Dissatisfaction with conventional medicine did not predict CAM use, nor did sex, age, income or race/ethnicity [11]. Finally, people turn to CAM because they believe mind/body therapies are important for health maintenance or simply because they find it an interesting concept worth experimentation [12].

Apart from gemstone therapy, medicine homeopathy, acupuncture, chiropractic, flower essences and radionics are also included in alternative medicine. Patients with inflammatory bowel disease, arthritis and mixed chronic conditions have used CAM, as was observed in a study that examined the patterns of provider-based CAM use across three chronic illness groups [13]. In addition, infections, constipation, diarrhea, pregnancy related issues [8], gynecological problems [14] and kidney stones have all been treated under the umbrella of CAM. Aquamarine water has been used to treat conditions such as arthritis and scleroderma [15].

An exhaustive literature search for gemstone therapy revealed a large body of unvalidated information on the internet. The search for published and validated materials on the subject in peer reviewed medical journals was, however, not as fruitful. No large clinical studies have been carried out on this subject to date. During our literature search, we found only one study that was done to evaluate the effects of Hessonite on MDA MB 231 human breast cancer cells. The study suggested an inhibitory effect of Hessonite on these cancer cells [16].

Gemstone therapy's long history is documented in ancient texts. For example, in ancient Vedic texts from India, the origin and healing powers of various gems are described [3]. Similarly, Unani (Greek) texts detail disease treatments with pulverized gemstones [17].

Gemstone therapy is most commonly practiced as either electronic gem therapy or colour/radiation gem therapy. Notably, these are the only therapies for which some evidence is available regarding their application in alternative medicine. Color/stone radiation therapy uses an accelerated process of light projection and is believed to aid in the acceleration of healing processes [18] while electronic gem therapy uses dielectric resonating properties of gemstones to induce energy into diseased or injured tissues [19].

Believers in gemstone therapy feel that all gemstones carry certain vibrations and channel good energy. When the gem or stone is placed within a person's "aura", it can change the mental and physical outlook of the wearer. [4] "Crystal Healing" is also believed to help absorb, diffuse and focus energy into the body [13]. "Chakra" therapies involve a gemstone being placed on major and minor chakra points of the body to restore balance and vitality to the human system [20].

Gemstones are believed to be helpful in a number of disease states. Renal and gallstones have been particularly traditionally treated through gemstone therapy; this may be because of the correspondence in the state of matter between renal stones, gallstones and gemstones. In addition to enhancing physical and psychological well being, gemstones are purported to influence fortunes and finances. Some believe they evoke emotions, virtues and sexuality $[3,4,20]$. Proponents of gemstone therapy also advocate it as a much healthier and natural alternative to healing than taking prescription medication [4]. Although not dismissing these claims as superstitious, we should recognize that they largely emerge from anecdotal and traditional beliefs - sources of knowledge that are different from peer reviewed medical literature.

Pakistan currently has a pluralistic health care system where a number of components are involved in the delivery of heath care to the public. Financial constraints are an important consideration in the choice of the health care system [21]. We believe that gemstone therapy is a popular modality of therapy amongst the Pakistani population; though we have no baseline data on the subject. Our opinion and observation is based on patient accounts in 
clinical encounters and discussion with colleagues on gemstone therapy.

An integration of alternative and conventional medicine can go a long way in improving the health status of the population and subsequently improving their quality of life [22]. But for this purpose, treatments offered by alternative medicine need to be scientifically evaluated to make them evidence based. Our understanding of the perceived healing powers of gemstones is still incomplete. As a first step, we need to explore the knowledge, attitudes and practices of users of gemstone therapeutics to see whether it warrants scientific evaluation based on prevalence alone. Experiments could then be planned to study effects of gemstone therapy [3].

\section{Methods Study Design and Study Site}

We conducted a knowledge, attitude and practices (KAP) survey at the Community Health Centre (CHC) at The Aga Khan University Hospital (AKUH), Karachi, Pakistan. AKUH is a tertiary level teaching facility in the private sector and caters to the medical needs of a large majority of patients coming from all over Karachi. The waiting area of the CHC clinics was chosen as the study setting because it is attended by a large number of people from all walks of life daily and hence caters to patients from almost all socioeconomic classes. The CHC not only runs family medicine clinics, but also provides specialist services to a multitude of patients.

\section{Study Sample and Data Collection}

We required a sample size of 420 to fulfill our objectives at a $95 \%$ confidence interval, and 5\% sample error. This sample size was calculated assuming a $50 \%$ variance and adjusting for a $10 \%$ non-response rate. Convenience sampling was used to draw the sample. All consenting individuals, visiting the CHC between $11 \mathrm{am}$ to $6 \mathrm{pm}$ and falling in the age bracket of completed 18 to completed 75 years of age were interviewed. Information was collected using face-to-face interviews based on a structured, pre-tested questionnaire. Informed consent for participation in the survey was obtained from the respondents of the survey. Strict confidentiality was maintained throughout the process of data collection, entry and analysis. The time period for data collection was two months (January 2008 to March 2008). The questionnaire was thoroughly discussed among the interviewers before data collection to decrease interview bias.

\section{Questionnaire a. Development}

The initial questionnaire was developed based on the prior experience of investigators, input from colleagues, peers as well as patients. The initial framework of the questionnaire was then expanded by incorporation of new aspects encountered during an extensive literature search. The draft so prepared was then pre-tested on 25 respondents and no changes were deemed necessary to be made in the questionnaire based on this pre-testing. The results of the pre-testing were not included in the final analysis of the data. A meeting of the investigators was held prior to the administration of the questionnaire in order to maintain uniformity in its administration; hence reducing chances of interviewer's bias in the study.

\section{b. Sections}

The questionnaire was divided into four sections. [see Additional file 1]

\section{Section I}

The first section comprised of socio-demographic information. Education status was categorized into different groups ranging from illiterate (being the most uneducated) to post graduate (being the highest level of education). Therefore, "education upto class 12 " is the category that includes people who had education only upto grade 12 but not beyond. Other categories were similarly delineated.

\section{Section 2}

Section 2 assessed the knowledge of respondents regarding gemstone therapy. This was assessed via questions related to the use of gemstones for their affects on health, identification of areas of health where gemstones are used like treatment of gall stones, renal stones or other(s) that the respondents might know of, methods of use of gemstones and source(s) of information regarding gemstone therapeutics.

\section{Section 3}

Section 3 comprised of questions assessing the attitudes of respondents regarding therapeutic use of gemstones. These questions related to opinions regarding beliefs about the impact of gemstones on health, finance, physical strength, longevity or other factor(s), whether the use of gemstones for health improvement is a superstitious or religious belief.

\section{Section 4}

Section 4 comprised of questions assessing the practices of respondents regarding therapeutic use of gemstones Questions dealing with areas such as advice and use of gemstones for therapeutic purposes were included.

\section{Statistical Analysis}

Data was entered and validated using Epi-data version 3.1. It was cleaned for invalid and out of range values, missing values and duplicate ID numbers. The data was then imported to Windows Statistical Package for Social 
Sciences (SPSS) version 15.0 using DBMS. The data was analyzed using Windows SPSS version 15.0. As part of descriptive statistics, mean, median and mode were used to express the data collected. Associations were assessed using Chi-square test. P values were determined; a P-value $<0.05$ was considered significant. Sociodemographic variables with a significant $\mathrm{p}$ value in chi square testing were subjected to a multiple logistic regression analysis to determine which factors were independent predictors of awareness of use of gemstones and the belief that gemstones impact health. All odds ratios were recorded with a 95\% confidence interval. Tables and figures were used for an all-inclusive viewing of the results.

\section{Ethical Considerations}

All efforts were made in this study to fulfill the ethical considerations in accordance with the Delcaration of Helsinki [23]. The confidentiality of each participant was strictly ensured throughout the project. The study was approved by the Ethical Review Committee at the Department of Community Health Sciences Department, Aga Khan University Hospital.

\section{Results}

\section{Descriptive Statistics}

Socio-demographic Characteristics of Study Population

We approached a total of 465 individuals for our survey, 45 of them declined to participate in the study. Of the 420 individuals who agreed to participate in the survey, 400 completed the interview. The response rate of the study was $86 \%$. Table 1 describes the socio-demographic characteristics of our study population $(\mathrm{n}=400)$. Females, people belonging to 29-39 years of age, those who were married, had income $>10,000-50,000$ Rs. and graduates/postgraduates were in majority.

\section{Knowledge Variables of Gemstone Therapy}

As shown in table 2, 252 individuals (63\%) in our study population were aware of the use of gemstone therapy for various effects on health. In contrast, only $111(28 \%)$ of the respondents were aware of any method of gemstone use other than wearing a ring or necklace. Of the people who were aware of other methods of using gemstones than rings or necklaces; $51 \%$ reported earrings, $26 \%$ wrist band and 5\% arm bands. With regards to the use of gemstones in treating various ailments, the majority reported that gemstones are helpful in improving gallstones and renal stones; followed by those who held similar beliefs for hypertension, skin diseases and reproductive health. Out of 400 respondents, $46 \%$ of the people didn't know if gemstones are helpful in any disease state.

\section{Belief Variables of Gemstone Therapy}

Of the 156(39\%) people who expressed a belief that gemstones have an impact on health, $48 \%$ believed that gem-
Table I: Socio demographics of the respondents

\begin{tabular}{lcc}
\hline Respondents & $\begin{array}{c}\text { Frequency } \\
(\mathrm{n}=400)\end{array}$ & $\%$ \\
\hline Gender & & \\
\hline Males & 195 & 48.8 \\
\hline Females & 205 & 51.2 \\
\hline
\end{tabular}

Mean Age in years

Males/Females $43.17 / 35.43-$

Standard Deviation $\pm|3.489 /| 1 \mid .856$

Age Distribution (yrs)

\begin{tabular}{lcc}
\hline $1.18-28$ & 103 & 25.8 \\
\hline $2.29-39$ & 126 & 31.5 \\
\hline $3.40-50$ & 79 & 19.7 \\
\hline $4.51-61$ & 67 & 16.8 \\
\hline $5.62-72$ & 25 & 6.2 \\
\hline
\end{tabular}

Marital status

\begin{tabular}{lcc}
\hline I. Currently single & 155 & 38.8 \\
\hline 2. Married & 245 & 61.2 \\
\hline
\end{tabular}

Income (in rupees)

\begin{tabular}{lcc}
\hline I. $<5000$ & 45 & 11.2 \\
\hline 2. $5000-10,000$ & 94 & 23.5 \\
\hline 3. $>10,000-50,000$ & 206 & 51.5 \\
\hline 4. $>50,000-100,000$ & 43 & 10.8 \\
\hline 5. $>100,000$ & 12 & 3
\end{tabular}

Occupation

\begin{tabular}{lcc}
\hline I. Currently Employed & 216 & 54 \\
\hline 2. Currently Unemployed & 184 & 46 \\
\hline
\end{tabular}

Level of education 
Table I: Socio demographics of the respondents (Continued)

\begin{tabular}{lcc}
\hline I. Till class I2 & 145 & 36.2 \\
\hline 2. Graduate/Postgraduate & 224 & 56 \\
\hline 3. Can only read and write name & 7 & 1.8 \\
\hline 4. Illiterate & 6 & 1.5 \\
\hline 5. Diploma & 18 & 4.5 \\
\hline
\end{tabular}

stones only have a favorable impact on health while 39\% believed that gemstone use can exert both favorable and adverse impacts on health. Out of 400 respondents, 34\% of the respondents believed that gemstones have an impact on luck only while $21 \%$ believed that gemstones can impact both fortune and luck. Seventeen percent people believed that gemstones don't influence either luck or finances. Table 3 provides the remaining details of belief variables regarding gemstone therapy.

\section{Advice Variables of Gemstone Therapy}

Of the 157 people who had been advised to use a gemstone for a positive impact on health, 33\% had been advised by friends, $22 \%$ by siblings and $20 \%$ by either aunts or uncles. Less than $1 \%$ had been advised by their grandparents. Of the 166 respondents who reported that someone among their friends of family members was using gemstones to improve their health, $24 \%$ reported friends, $18 \%$ siblings, $27 \%$ reported aunts or uncles who were currently using gemstones. $42 \%$ of the relatives had used ruby/yaqoot/marjan or aqeeq while $11 \%$ had used a diamond. 33\% had used aquamarine, turquoise or feroza. $55 \%$ of the relatives had experienced a favorable impact from the use of gemstones while $31 \%$ had experienced both adverse and favorable effects. Out of the 80 respondents who had ever advised anyone to use gemstones for a positive impact on health, $65 \%$ had advised friends, $21 \%$ parents and 5\% had advised siblings. Out of the same 80 individuals, $50 \%$ had advised the use of ruby/aqeeq/ yaqoot or marjan while $25 \%$ had advised the use of sapphire and $11 \%$ had advised the use of pearl. Of the 142 who expressed a willingness to advise others about the use of gemstones, $63 \%$ said they would advise friends, $18 \%$ siblings, and $12 \%$ parents. $55 \%$ said that they would advise the use of ruby/aqeeq/yaqoot or marjan while $13 \%$ said that they would advocate the use of sapphire. Up to 93\% people believed that people advised would get a favorable impact on their health secondary to using gemstones while $6 \%$ people believed that both adverse and beneficial effects would be the anticipated impact.

\section{Practice Variables of Gemstone Therapy}

Of the 152 people who reported using a gemstone in the past for a favorable impact on health; $49 \%$ had used a ruby/aqeeq/yaqoot or marjan and only $2 \%$ reported using an emerald. Wearing a ring was the most popular way of using a gemstone with $84 \%$ people reporting its use. $44 \%$ of 152 people had used it for a period of $1-5$ years while $20 \%$ of the people had used gemstones for less than a year. $51 \%$ of the people who had used a gemstone reported experiencing a favorable impact on their health, while $40 \%$ had experienced both favorable and adverse impacts on their health as a result of using gemstones. Of the 96 people who reported current use of gemstones, $63 \%$ reported using a ruby/yaqoot/aqeeq or marjan while $12 \%$ reported using sapphire and $7 \%$ reported use of pearl. Up to $92 \%$ people reported using the gemstone in a ring. Out of the current users of gemstones, 35\% had been using it for 1-5 years while $30 \%$ had been using it for less than a year. 53\% of the current users of gemstones had experienced a favorable impact while $32 \%$ had reported experiencing both favorable and adverse impact on health secondary to gemstone use. With regards to the shape of the gemstone, 64\% said that their therapeutic gemstone has no specific shape while the majority $(22 \%)$ reported wearing a spherical gemstone. $72 \%$ of the respondents have always worn the same color of the gemstone and out of these, $40 \%$ have used red gemstones, $17 \%$ blue, $17 \%$ brown, and $9 \%$ turquoise. $75 \%$ people have never considered wearing a combination of different colored gemstones. $54 \%$ of the people usually wear a gemstone ring on their ring finger while $27 \%$ wear it on the second finger of the hand. Only $26 \%$ people believe that gemstones change color with one's state of health while $55 \%$ people had never heard of this transition.

$34 \%$ people said that gemstone therapeutics had sometimes worked out the right way for them, while $48 \%$ individuals gave a "don't know response". Out of the 40 people who had considered using a cheap substitute for the original gemstones, only $12(30 \%)$ found the substitutes to be as beneficial as the originals. Most of the people had heard about gemstone therapeutics by word of mouth with 59\% reporting hearing it from other people, friends, colleagues or family members. Magazines were accredited as a source of information by $19 \%$ and other media (such as television and radio) by about $15 \%$ of the respondents (Figure 1).

\section{Chi square/Fisher's Exact Test Results}

The belief that gemstones have an impact on health was significantly associated with the use of gemstones ( $p$ value $=<0.001)$, advising others to use gemstones in the future ( $p$ value $=<0.001$ ) and duration of time for which gemstones were used ( $p$ value $=0.028)$. It was also significantly associated with age ( $\mathrm{p}$ value $=<0.001)$, gender $(\mathrm{p}$ 
Table 2: Knowledge Variables

\begin{tabular}{|c|c|c|}
\hline Knowledge Variables & Frequency & $\%$ \\
\hline \multicolumn{3}{|c|}{ Awareness of use of gemstones for effects on health: $(n=400)$} \\
\hline Yes & 252 & 63 \\
\hline No & 215 & 31.2 \\
\hline Don't Know & 23 & 5.8 \\
\hline \multicolumn{3}{|c|}{ Awareness of methods of gemstone use other than wearing a ring or necklace: $(n=400)$} \\
\hline Yes & 111 & 27.8 \\
\hline No & 179 & 44.7 \\
\hline Don't Know & 110 & 27.5 \\
\hline \multicolumn{3}{|c|}{ Awareness of the use of gemstones in different diseases $(n=216) *$} \\
\hline Gallstones/Renal Stones & 111 & 51.4 \\
\hline Diabetes & 47 & 21.8 \\
\hline Hypertension & I & 0.5 \\
\hline Skin & 29 & 13.4 \\
\hline Reproductive Health & 25 & 11.6 \\
\hline Others & 3 & 1.3 \\
\hline
\end{tabular}

* 216 individuals out of 400 were aware of use of gemstones in different disease states. The percentages for this variable have therefore been computed for a total of 216 respondents.

value $=<0.001)$, education $(\mathrm{p}$ value $=0.004)$, occupation ( $\mathrm{p}$ value $=<0.001)$ and socioeconomic status ( $\mathrm{p}$ value $<$ 0.001). [Table 4]

Receiving advice about gemstone use in the past was significantly associated with advising others of gemstone use in the future ( $\mathrm{p}$ value $=0.020$ at $95 \% \mathrm{CI}$ ). Gender, education, occupation and socioeconomic status were significantly associated with the opinion that gemstone use for health improvement is based on a superstitious belief (Gender: p value $=0.002$, Education: $p$ value $=<0.001$, Occupation: $\mathrm{p}$ value $=0.023$ and Socioeconomic status: $\mathrm{p}$ value $=0.002$ ). [Table 5] Age, education, occupation and socioeconomic status were significantly associated with the opinion that use of gemstones for health improvement is based on religious beliefs (Age: $p$ value $=0.020$, Education: $\mathrm{p}$ value $=<0.001$, Occupation: $\mathrm{p}$ value $=<$ 0.001 and SES: $p$ value $=0.008)$. [Table 6]

Use of gemstones for effects on health was significantly associated with age ( $\mathrm{p}$ value $=<0.001)$, marital status ( $\mathrm{p}$ value $=<0.001)$, occupation ( $\mathrm{p}$ value $=<0.001)$ and use of gemstones by friends or family members ( $\mathrm{p}$ value $=<$ 0.001). [Table 7]
Awareness of the use of gemstones for health was not significantly associated with the belief that gemstones have an impact on health ( $\mathrm{p}$ value $=0.580$ ) or past use of a gemstone $(\mathrm{p}$ value $=0.228)$. Age $(\mathrm{p}$ value $=0.001)$, education $(\mathrm{p}$ value $=<0.001)$, and income $(\mathrm{p}$ value $=0.002)$ were, however, all significantly associated with the awareness that gemstones are used for their effects on health. [Table 8]

\section{Multiple Logistic Regression}

The following variables were subjected to the multiple regression analysis: 'age', 'education', 'occupation' and 'income'. Table 9 shows the independent predictors of awareness of use of gemstones for their impact on health. The significant $(p<0.05)$ independent predictors of awareness of use of gemstone therapy included: age $>39$ years, education $>$ grade 5 , income $>$ Rs.50,000.

Table 10 shows the independent predictors of belief that gemstones use has an impact on health. Following were significant $(p<0.05)$ independent predictors of the belief that gemstones have an impact on health: male gender, age $>28$ years, married, education up to grade 5, currently employed and income > Rs. 5,000. 
Table 3: Belief Variables

\begin{tabular}{lcc}
\hline Belief Variables & $\begin{array}{c}\text { Frequency } \\
(n=400)\end{array}$ & $\%$ \\
\hline
\end{tabular}

Belief that gemstones have an impact on health

\begin{tabular}{lcc}
\hline Yes & 156 & 39 \\
\hline No & 218 & 54.5 \\
\hline Don't Know & 26 & 6.5 \\
\hline
\end{tabular}

Belief that gemstones increase physical strength

\begin{tabular}{lcc}
\hline Yes & 154 & 38.5 \\
\hline No & 93 & 23.2 \\
\hline Don't Know & 153 & 38.2 \\
\hline
\end{tabular}

Opinion that gemstone use is a superstitious belief

\begin{tabular}{lcc}
\hline Yes & 247 & 61.8 \\
\hline No & 98 & 24.5 \\
\hline Don't Know & 55 & 13.8 \\
\hline
\end{tabular}

Opinion that gemstone use is based on religious beliefs

\begin{tabular}{lcc}
\hline Yes & 110 & 27.5 \\
\hline No & 98 & 24.5 \\
\hline Don't Know & 192 & 48 \\
\hline
\end{tabular}

Belief that gemstones change colors with one's health

\begin{tabular}{lcc}
\hline Yes & 104 & 26 \\
\hline No & 78 & 19.5 \\
\hline Don't Know & 218 & 54.5 \\
\hline
\end{tabular}

\section{Discussion}

Correlations of socio-demographic variables with awareness, use, and belief towards gemstones demonstrate interesting findings. A higher prevalence of the awareness about the use of gemstones and their effects on health exists in individuals who are educated; with 89 out of 252 such respondents being graduates, and belonging to the middle class stratum of the society, with an income ranging from Rs. 10,000-50,000 (1 US \$ equivalent to 60.667 Pak rupee(PKR)). We also found a significant association between age and an awareness of the use of gemstones. The young population (29-39 years of age) had the high- est prevalence of awareness regarding the use of gemstones. The same age group also formed the majority of those who had used a specific gemstone, with $49 \%$ of them having used one of these gemstones - ruby, yaqoot, marjan, or aqeeq, as a ring (91\%). It was noted that $61 \%$ of those who believed in the healing power of gem therapy stated that using gemstones tends to have a favorable impact on health and mostly from those who had used a particular one. The belief that gemstones have an impact on health was also found to be significantly associated with age, gender, education, occupation, marital status, and socioeconomic status (SES) of the respondents.

Other important implications can be derived from the significant associations we found between advice and use of gemstones. Of the $39 \%$ of those who had used gemstones or $38 \%$ of those who held any beliefs regarding their use, around one-third (36\%) stated that they would advise others about use of gemstones, mostly their friends (63\%). It was observed that $49 \%$ of those who had been advised about the use of gemstones showed an inclination towards their future use. An interesting association between marital status and level of education was observed with the desire to advise others to use gemstones for their effects on health. Married and educated people showed greater inclination to advise someone in the future about the use of gemstones.

The majority of the people reported that gemstones are helpful in improving gallstones, renal stones, hypertension, skin diseases, and reproductive health. A literature search revealed that gemstone therapy is believed to have beneficial effects on the course of chronic diseases, such as migraine, asthma, tumors, backaches, hypertension, kidney diseases and stones, piles, and arthritis [4].

In our survey, different people reported wearing different stones. This difference in practices is explainable by the fact that different stones are believed to be helpful in different disease states. Wearing a ring emerged as the most popular way of using a gemstone. Gemstones are sported in different ways. One source reported that the best way for the increased efficiency of gemstone therapy is to sport them at the fingers. The fingers are believed to have direct channels to the centers of the human body. For exact balancing of the negative and positive energies of centers, different kinds of gems may be worn [4].

Those who showed willingness to use a therapeutic gemstone in the future mentioned that the use of or advice by family members was the main reason for their willingness. When inquired about anyone they know who uses a gemstone, $41 \%$ of these respondents reported the use of a gemstone by a friend or a family member. This constitutes a type of "lay referral system," whereby people are 


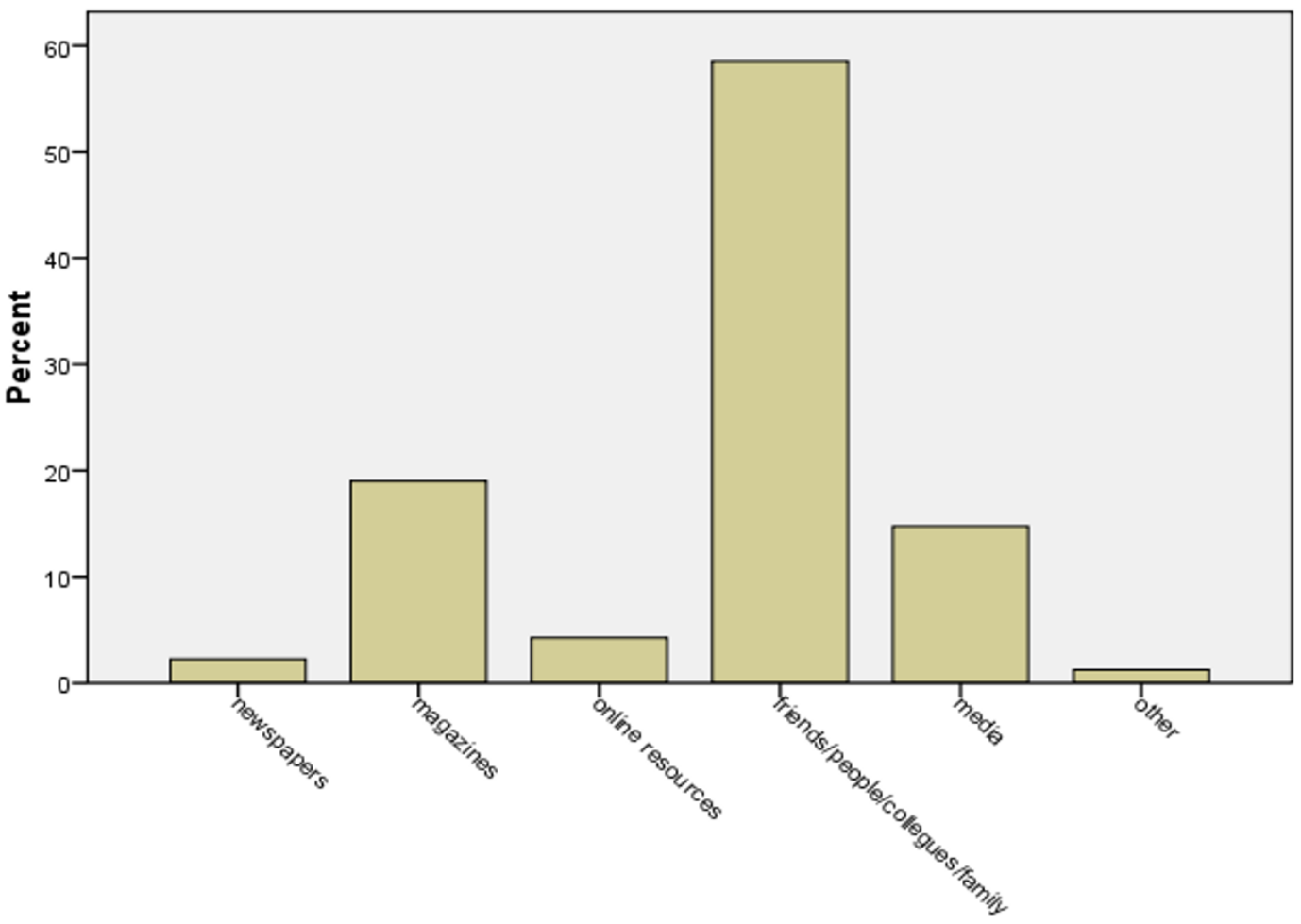

Source of Information for Gemstone Therapy

\section{Figure I}

Source of Information for Gemstone Therapy.

inclined to try out a treatment based on word of mouth from an acquaintance. In another study, the most common reason for using CAM was being taught to do so by family members [8]. Opting for CAM use stems from an intricate interaction of an array of dynamic factors that reflect variations in sociocultural factors influencing reasoning, illness comprehension, treatment-seeking behaviors, motivations, attitudes, and availability. Factors, such as residence in rural areas, acceptability of service, cooperation, empathetic attitude and active listening by the traditional healers as compared to conventional health care professionals, [21,24] also play a part. In Pakistan, the joint family system is prevalent; elders pass down their life experiences as part of a legacy to their children and advise them about what they have found beneficial in their lives. Besides family advice and pressure, other reasons for consulting a CAM healer could be the proximity, affordable fee, availability of the provider, and the strong opinion of the community [21].

Almost an equal number of respondents believed that gemstone therapy can have a role in improving one's health as well as physical strength. Out of these, a signifi- cant majority did not know if gemstones changed colour with one's state of health, reflecting that people in this part of the world are yet not aware of the scientific basis of gemstone/colour therapy; the majority having used a specific gemstone (specially red/brown stone) because it was either used or advised by someone by a friend or family member, reinforcing the aforementioned statement regarding the significance of 'lay referral' system in this country. Therefore we feel that there is a need to educate people regarding the actual basis of therapeutic benefits of gemstone therapy and how this energy medicine offers solutions to seemingly intractable health problems.

An almost bi-modal trend was observed regarding the effects of gemstones; respondents reported favorable effects as well as 'both favorable and adverse' effects experienced from using the gemstones, $(78 \%$ and $61 \%$, respectively). This is consistent with different beliefs regarding gemstone therapy; some stones are believed to channel positive energy while others are believed to have adverse effects as mentioned earlier. Except for the $4 \%$ of the respondents who reported that gemstones had never 
Table 4: Associations of belief that gemstones have an impact on health

\begin{tabular}{|c|c|c|c|c|}
\hline \multirow[t]{2}{*}{ Variables } & \multicolumn{4}{|c|}{ Belief that gemstones have an impact on health } \\
\hline & Yes & No & Don't Know & P-values \\
\hline \multicolumn{5}{|l|}{ Use of Gemstones $(n=400)$} \\
\hline Yes & 98 & 46 & 8 & $<0.001$ \\
\hline No & 58 & 172 & 18 & \\
\hline \multicolumn{5}{|c|}{ Advising Others to Use Gemstones in Future $(n=400)$} \\
\hline Yes & 68 & 65 & 9 & $<0.001$ \\
\hline No & 63 & 148 & 16 & \\
\hline Don't Know & 156 & 5 & 1 & \\
\hline \multicolumn{5}{|c|}{ Duration of Gemstone Use $(n=152) *$} \\
\hline$-<$ I year & 25 & 3 & 3 & \\
\hline$-1-5$ years & 38 & 26 & 3 & 0.028 \\
\hline$-5-10$ years & 18 & 14 & 1 & \\
\hline - > 10 years & 17 & 3 & 1 & \\
\hline \multicolumn{5}{|l|}{ Gender $(n=400)$} \\
\hline Male & 82 & 111 & 2 & $<0.001$ \\
\hline Female & 74 & 107 & 24 & \\
\hline \multicolumn{5}{|l|}{ Socioeconomic Status $(n=400)$} \\
\hline$<5,000$ Rs & 12 & 30 & 3 & $<0.001$ \\
\hline $5-10,000$ Rs & 34 & 49 & 11 & \\
\hline $10-50,000 \mathrm{Rs}$ & 74120 & 12 & & \\
\hline$>50,0000$ Rs & 36 & 19 & 0 & \\
\hline \multicolumn{5}{|l|}{ Education $(n=400)$} \\
\hline Can only read and write name & 11 & 0 & 2 & \\
\hline Upto Class 8 & 7 & 15 & 0 & 0.004 \\
\hline Upto Class 12 & 42 & 73 & 8 & \\
\hline Graduate/Post graduate/Diploma & 96 & 130 & 16 & \\
\hline Age in years $(n=400)$ & & & & \\
\hline
\end{tabular}


Table 4: Associations of belief that gemstones have an impact on health (Continued)

\begin{tabular}{|c|c|c|c|c|}
\hline $18-28$ & 17 & 74 & 12 & $<0.001$ \\
\hline $29-39$ & 52 & 64 & 10 & \\
\hline $40-50$ & 41 & 36 & 2 & \\
\hline $5 I-6 I$ & 36 & 29 & 2 & \\
\hline $62-72$ & 10 & 15 & 0 & \\
\hline \multicolumn{5}{|c|}{ Occupation $(n=400)$} \\
\hline Student & 1 & 37 & 3 & \\
\hline Self-employed & 26 & 43 & 3 & \\
\hline Private Service & 36 & 51 & 3 & \\
\hline Government Service & 19 & 27 & 3 & $<0.001$ \\
\hline Unemployed & 0 & 2 & 4 & \\
\hline Retired & 15 & 12 & 0 & \\
\hline Housewife & 57 & 43 & 10 & \\
\hline Others & 2 & 3 & 0 & \\
\hline
\end{tabular}

* 152 individuals out of 400 had used gemstones in the past for effects on health. Therefore, association for duration of usage is reported for these 152 people.

worked out the right way for them, the majority expressed satisfaction with gemstone therapy.

Categorizing the use of gemstones as being based on either superstitious or religious beliefs emerged as a controversial issue. $62 \%$ of the respondents agreed that the use of gemstones is based on superstitious beliefs. However, only about $28 \%$ of the respondents stated religious beliefs as a basis for gemstone use. The belief that use of gemstones is based on superstition had a strong association with gender, SES, occupation and education of the respondents. On the other hand, the opinion that use of gemstones is based on religious beliefs was significantly associated with education, occupation and SES.

\section{Strengths and limitations}

To the best of our knowledge, this study is the first of its kind and provides a valuable insight into the reasons motivating people to use gemstones. Additionally, our questionnaire on assessing knowledge, attitudes and practices of gemstone therapeutics may be employed in future studies as a template for gauging similar parameters.

We also acknowledge the following limitations of our study. Firstly, we used convenience sampling to draw our sample. Convenience sampling is inferior to probability sampling in its representativeness of the population, and this limits the external validity of the study. Sampling from a single centre limits the generalizeabilty of the study. However, as mentioned before, $\mathrm{CHC}$ receives people from all socioeconomic classes, helping offset this limitation. Our findings are generalizable to a wider population because people in Pakistan simultaneously use different delivery systems of its pluralistic health system. Health seeking behavior is shaped by the type of symptoms experienced and the number of days of illness. Milder symptoms like fever are managed with home remedies or folk prescriptions, while more complex, prolonged or severe symptomatology is usually managed in consultation with biomedical health provider [21]. The respondents in the study had used gemstones either currently or previously and they were encountered while seeking medical advice from a medical doctor at $\mathrm{CHC}$ at AKUH, Karachi, Pakistan.

Hospital attendees were chosen for convenience of administration of interviews. We acknowledge that the knowledge, attitudes and practices of individuals presenting to the hospital may be different than those encountered in the community setting. 
Table 5: Association that gemstone use is based on superstitious beliefs

\begin{tabular}{|c|c|c|c|c|}
\hline \multirow[t]{2}{*}{ Variables } & \multicolumn{4}{|c|}{ Opinion that gemstone use for health improvement is based on a superstitious belief $(n=400)$} \\
\hline & Yes & No & Don't Know & p-values \\
\hline \multicolumn{5}{|l|}{ Gender } \\
\hline Male & 113 & 62 & 20 & 0.002 \\
\hline Female & 134 & 36 & 35 & \\
\hline \multicolumn{5}{|l|}{ Socioeconomic Status } \\
\hline$<5,000 \mathrm{Rs}$ & 35 & 6 & 4 & 0.002 \\
\hline $5-10,000$ Rs & 49 & 35 & 10 & \\
\hline $10-50,000 \mathrm{Rs}$ & 124 & 52 & 30 & \\
\hline$>50,0000 \mathrm{Rs}$ & 39 & 5 & 11 & \\
\hline \multicolumn{5}{|l|}{ Education } \\
\hline Can only read and write name & 7 & 2 & 4 & \\
\hline Upto Class 8 & 6 & 16 & 0 & $<0.001$ \\
\hline Upto Class 12 & 61 & 50 & 12 & \\
\hline Graduate/Post graduate/Diploma & 173 & 30 & 39 & \\
\hline \multicolumn{5}{|l|}{ Occupation } \\
\hline Student & 32 & 3 & 6 & \\
\hline Self-employed & 43 & 26 & 3 & 0.023 \\
\hline Private Service & 48 & 24 & 18 & \\
\hline Government Service & 33 & 10 & 6 & \\
\hline Unemployed & 5 & I & 0 & \\
\hline Retired & 20 & 5 & 2 & \\
\hline Housewife & 62 & 28 & 20 & \\
\hline Others & 4 & I & 0 & \\
\hline
\end{tabular}


Table 6: Association of gemstone use based on religious beliefs

\begin{tabular}{|c|c|c|c|c|}
\hline \multirow[t]{2}{*}{ Variables } & \multicolumn{4}{|c|}{ Opinion that gemstone use for health improvement is based on religious belief $(n=400)$} \\
\hline & Yes & No & Don't Know & p-values \\
\hline \multicolumn{5}{|l|}{ Age in years } \\
\hline $18-28$ & 25 & 31 & 47 & 0.02 \\
\hline $29-39$ & 29 & 30 & 67 & \\
\hline $40-50$ & 25 & 9 & 45 & \\
\hline $51-61$ & 20 & 21 & 26 & \\
\hline $62-72$ & 11 & 7 & 7 & \\
\hline \multicolumn{5}{|l|}{ Socioeconomic Status } \\
\hline$<5,000 \mathrm{Rs}$ & 13 & 11 & 21 & 0.008 \\
\hline $5-10,000$ Rs & 16 & 20 & 58 & \\
\hline $10-50,000 \mathrm{Rs}$ & 59 & 60 & 87 & \\
\hline$>50,0000$ Rs & 22 & 7 & 26 & \\
\hline \multicolumn{5}{|l|}{ Education } \\
\hline Can only read and write name & 4 & 3 & 6 & \\
\hline Upto Class 8 & 0 & 0 & 22 & $<0.001$ \\
\hline Upto Class 12 & 36 & 29 & 58 & \\
\hline Graduate/Post graduate/Diploma & 70 & 66 & 106 & \\
\hline \multicolumn{5}{|l|}{ Occupation } \\
\hline Student & 5 & 17 & 19 & \\
\hline Self-employed & 12 & 16 & 44 & $<0.001$ \\
\hline Private Service & 22 & 22 & 46 & \\
\hline Government Service & 8 & 10 & 31 & \\
\hline Unemployed & 4 & 1 & 1 & \\
\hline Retired & 16 & 6 & 5 & \\
\hline Housewife & 40 & 26 & 44 & \\
\hline Others & 3 & 0 & 2 & \\
\hline
\end{tabular}


Table 7: Association of use of gemstones with effects on health

\begin{tabular}{|c|c|c|c|}
\hline \multirow[t]{2}{*}{ Variables } & \multicolumn{3}{|c|}{ Use of gemstones for impact on health $(n=400)$} \\
\hline & Yes & No & p-values \\
\hline \multicolumn{4}{|l|}{ Age in years } \\
\hline $18-28$ & 18 & 85 & $<0.001$ \\
\hline $29-39$ & 49 & 77 & \\
\hline $40-50$ & 35 & 44 & \\
\hline $51-61$ & 39 & 28 & \\
\hline $62-72$ & II & 14 & \\
\hline \multicolumn{4}{|l|}{ Occupation Use } \\
\hline Student & 5 & 36 & \\
\hline Self-employed & 25 & 47 & $<0.001$ \\
\hline Private Service & 32 & 58 & \\
\hline Government Service & 21 & 28 & \\
\hline Unemployed & 0 & 6 & \\
\hline Retired & 17 & 10 & \\
\hline Housewife & 50 & 60 & \\
\hline Others & 2 & 3 & \\
\hline \multicolumn{4}{|l|}{ Marital Status } \\
\hline Married & 111 & 134 & \\
\hline Single & 34 & $106<0.001$ & \\
\hline Divorced & I & 0 & \\
\hline Widowed & 6 & 8 & \\
\hline \multicolumn{4}{|c|}{ Friends or Family Using Gemstones to Improve Health } \\
\hline Yes & 83 & 83 & \\
\hline No & 60 & $133<0.001$ & \\
\hline Don't Know & 9 & 32 & \\
\hline
\end{tabular}


Table 8: Awareness of the use of gemstones for their effects on health

\begin{tabular}{|c|c|c|c|c|}
\hline \multirow[t]{2}{*}{ Variables } & \multicolumn{4}{|c|}{ Awareness of the use of gemstones for their effects on health $(n=400)$} \\
\hline & Yes & No & Don't Know & p-values \\
\hline \multicolumn{5}{|l|}{ Age in years } \\
\hline $18-28$ & 65 & 36 & 2 & 0.001 \\
\hline $29-39$ & 80 & 31 & 15 & \\
\hline $40-50$ & 59 & 18 & 2 & \\
\hline $51-61$ & 33 & 32 & 2 & \\
\hline $62-72$ & 15 & 8 & 2 & \\
\hline \multicolumn{5}{|l|}{ Socioeconomic Status } \\
\hline$<5,000 \mathrm{Rs}$ & 30 & 15 & 0 & 0.002 \\
\hline $5-10,000$ Rs & 48 & 38 & 8 & \\
\hline $10-50,000 \mathrm{Rs}$ & 127 & 66 & 13 & \\
\hline$>50,0000$ Rs & 47 & 6 & 2 & \\
\hline \multicolumn{5}{|l|}{ Education } \\
\hline Can only read and write name & 1 & 8 & 4 & \\
\hline Upto Class 8 & 17 & 5 & 0 & $<0.001$ \\
\hline Upto Class 12 & 70 & 47 & 6 & \\
\hline Graduate/Post graduate/Diploma & 164 & 65 & 13 & \\
\hline
\end{tabular}

The information in the survey was acquired via a face-toface interview which was based on a questionnaire. While this may have led to higher rates of completion of the forms because of interviewer's encouragement for optimum completion, it may also have introduced interviewer's bias in the process of data collection despite all efforts to minimize it.

We did not ascertain the exact reason for which the respondents were attending the $\mathrm{CHC}$ clinics. Future studies can be undertaken to focus on this particular aspect to explore any correlations between the nature of health problem that brought them to the clinic and the use of gemstones. Also, the exact nature of the use of gemstone (cosmesis and aesthetics versus medical ailments) can be ascertained in greater detail in future studies. In addition, future studies can be done to explore the simultaneous use and associations, if any, of gemstone therapy and other modalities of CAM and how they may correlate to each other.

\section{Conclusion}

This study provides an insight into the knowledge, beliefs and practices with regards to use of gemstone therapy among the population. More than one third of our study population has used gemstones in the past while more than one fifth is currently using gemstones. More than half of our sample population is aware of the use of the gemstones for their various effects. Willingness to use gemstones is associated with the beliefs about the impact of gemstone therapy on health. Friends and family seem to be the major role players influencing people's willingness to use gemstones. Superstition and to a lesser extent, religion continue to have an impact on people's way of thinking with regards to gemstone therapy. 
Table 9: Multiple logistic regression for awareness of use of gemstones

\begin{tabular}{|c|c|c|c|}
\hline Variables & $\begin{array}{c}\text { Awareness } \\
\mathrm{n}=252(\%) \$\end{array}$ & Adjusted OR $*$ & $95 \% \mathrm{Cl} * *$ \\
\hline \multicolumn{4}{|c|}{ Age in years $(p=0.001)$} \\
\hline $18-28$ & $65(25.8)$ & 1 & \\
\hline $29-39$ & $80(31.8)$ & 1 & $0.6-1.7$ \\
\hline $40-50$ & $59(23.4)$ & 1.7 & $0.9-3.3$ \\
\hline $5|-6|$ & $33(13.1)$ & 0.6 & $0.3-1.1$ \\
\hline $62-72$ & $15(5.9)$ & 0.9 & $0.4-2.2$ \\
\hline \multicolumn{4}{|c|}{ Education $(p=0.000)$} \\
\hline Up to grade 5 & $13(5.2)$ & 1 & \\
\hline Up to grade 8 & $5(1.9)$ & 1.8 & $0.4-9.1$ \\
\hline Up to grade 12 & $70(27.8)$ & 1.4 & $0.6-3.3$ \\
\hline Beyond grade 12 & $164(65.1)$ & 2.3 & $1.0-5.1$ \\
\hline
\end{tabular}

\section{Occupation $(p=0.093)$}

\begin{tabular}{|c|c|c|c|}
\hline Currently unemployed & $117(46.4)$ & I & \\
\hline Currently employed & $135(53.6)$ & 1.1 & $0.6-1.8$ \\
\hline \multicolumn{4}{|c|}{ Monthly income in rupees $(p=0.004)$} \\
\hline$<5,000$ & $30(11.9)$ & 1 & \\
\hline $5,000-10,000$ & $48(19)$ & 0.5 & $0.3-1.1$ \\
\hline $10,000-50,000$ & $127(50.4)$ & 0.8 & $0.4-1.6$ \\
\hline$>50,000$ & $47(18.7)$ & 3 & $1.1-7.8$ \\
\hline
\end{tabular}

$*$ OR $=$ Odds Ratio

** $\mathrm{Cl}=$ Confidence Interval

$\$ 252$ out of 400 people were aware of use of gemstones for effects on health.

Today, alternative tools for transforming health are being embraced by a larger number of people, and many countries now have pluralistic health care systems. CAM modalities have excited the interest of physicians and medical researchers alike. In a time when we are all looking for a cure and realizing that many of the traditional treatment methods are not only laden with side effects, but simply may not work as well as expected, gemstone therapy certainly warrants scientific inquiry.
We should acknowledge that CAM is an art mushrooming throughout the world and many people regard it as a panacea for their problems. Ignorance on the part of conventional medical practitioners about these practices poses the serious risk of alienating the public [12]. Based on our findings, we propose gathering validated information with regards to a multifaceted phenomenon such as gemstone therapy - this might open new vistas in the field of medicine and benefit a larger number of patients. 
BMC Complementary and Alternative Medicine 2009, 9:32

Table 10: Multiple logistic regression for belief that gemstones impact health

\begin{tabular}{|c|c|c|c|}
\hline Variables & $\begin{array}{c}\text { Belief }(n=156) \\
n(\%)^{\$}\end{array}$ & Adjusted OR* & $95 \% \mathrm{Cl} * *$ \\
\hline \multicolumn{4}{|l|}{ Gender $(p=0.000)$} \\
\hline Male & $82(52.7)$ & 1 & \\
\hline Female & $74(47.3)$ & 0.8 & $0.5-1.2$ \\
\hline \multicolumn{4}{|l|}{ Age in years $(p=0.000)$} \\
\hline $18-28$ & $17(10.9)$ & 1 & \\
\hline $29-39$ & $52(33.3)$ & 3.6 & $1.9-6.8$ \\
\hline $40-50$ & $41(26.3)$ & 5.5 & $2.8-10.8$ \\
\hline $5|-6|$ & $36(23.1)$ & 5.9 & $2.9-11.9$ \\
\hline $62-72$ & $10(6.4)$ & 3.4 & $1.3-8.8$ \\
\hline \multicolumn{4}{|l|}{ Marital Status $(p=0.000)$} \\
\hline Divorced/Widowed/Separated & $5(3.2)$ & 1 & \\
\hline Married & $120(76.9)$ & 1.9 & $0.6-5.8$ \\
\hline Single† & $31(19.9)$ & 0.6 & $0.2-1.8$ \\
\hline \multicolumn{4}{|l|}{ Education $(p=0.004)$} \\
\hline Up to grade 5 & $14(8.9)$ & 1 & \\
\hline Up to grade 8 & $4(2.7)$ & 0.9 & $0.2-4.5$ \\
\hline Up to grade 12 & $42(26.9)$ & 0.5 & $0.2-1.1$ \\
\hline Beyond grade 12 & $96(61.5)$ & 0.6 & $0.3-1.4$ \\
\hline \multicolumn{4}{|l|}{ Occupation $(p=0.000)$} \\
\hline Currently unemployed & $73(46.8)$ & 1 & \\
\hline Currently employed & $83(53.2)$ & 2.3 & $1.2-4.2$ \\
\hline \multicolumn{4}{|c|}{ Monthly income in rupees $(p=0.001)$} \\
\hline$<5,000$ & $12(7.7)$ & 1 & \\
\hline $5,000-10,000$ & $34(21.8)$ & 1.6 & $0.7-3.4$ \\
\hline $10,000-50,000$ & $74(47.4)$ & 1.5 & $0.7-3.2$ \\
\hline$>50,000$ & $36(23.1)$ & 5.2 & $2.2-12.4$ \\
\hline$*$ OR $=$ Odds Ratio & & & \\
\hline
\end{tabular}




\section{Abbreviations}

AKUH: Aga Khan University and Hospital; CHC: Community Health Centre; SES: Socioeconomic Status

\section{Competing interests}

The authors declare that they have no competing interests.

\section{Authors' contributions}

SI was involved in study conception, data collection, entry, analysis, revision and manuscript writing. TS was involved in study conception, data collection, entry, analysis, revision and manuscript writing. WQ was involved in study conception, manuscript writing, revision, editing and overall supervision. All authors have read and approved the final manuscript.

\section{Additional material}

\section{Additional file 1}

Questionnaire of Survey. This is the questionnaire used for the survey to gauge the knowledge, attitudes and practices of the selected adult population about gemstone therapeutics.

Click here for file

[http://www.biomedcentral.com/content/supplementary/14726882-9-32-S1.doc]

\section{Acknowledgements}

We are thankful to Dr. Iqbal Azam, Department of Community Health Sciences, Aga Khan University for tutoring the use of SPSS.

The authors would also like to express their gratitude to Jesse Turner (MS III at Emory Medical School, Atlanta, Georgia) and Laney Weber (PhD at BioScience Writers) for reviewing the manuscript with regards to correction of syntax and language errors.

\section{References}

I. Definition of gemstone, YourDictionary.com [http:// www.yourdictionary.com/gemstone]

2. Don Clark CSM: International Gem Society. [http://www.gem society.org/info/igem 2.htm].

3. The Ayurveda Encyclopedia [http://hinduism.about.com/library/ weekly/extra/bl-gemshp.htm]

4. Miller D: Does Gem Therapy Work? The Arguments for and Against Gem Therapy as Alternative Medicine Treatment. [http://www.associatedcontent.com/article/30249/ does gem therapy work.html].

5. Barnes PM, Powell-Griner E, McFann K, Nahin RL: Complementary and alternative medicine use among adults: United States, 2002. Adv Data 2004, 343:I-19.

6. Zollman C Vickers A: ABC of complementary medicine: what is complementary medicine? $\mathrm{Br}$ Med J 1999, 319:693-6.

7. Bodeker G, Kronenberg F: A Public health agenda for traditional, complementary, and alternative medicine. Am J Publ Health 2002, 92: | 582-9|.

8. Trangmar P, Diaz VA: Investigating complementary and alternative medicine use in a Spanish-speaking Hispanic community in South Carolina. Ann Fam Med 2008, 6(SuppI I):SI2-5.

9. World Health Organization: Traditional Medicine Strategy 2002-2005. Geneva: WHO; 200I.

10. Sirois FM: Motivations for consulting complementary and alternative medicine practitioners: a comparison of consum- ers from 1997-8 and 2005. BMC Complement Altern Med 2008, 8:16.

II. Astin JA: Why patients use alternative medicine results of a national study. JAMA 1998, 279:1548-53.

12. Mehta Darshan H, Phillips Russell S, Davis Roger B, McCarthy Ellen P: Use of Complementary and Alternative Therapies by Asian Americans. Results from the National Health Interview Survey. J Gen Intern Med 2007, 22:762-767.

13. Sirois FM: Provider-based complementary and alternative medicine use among three chronic illness groups: associations with psychosocial factors and concurrent use of conventional health-care services. Complement Ther Med 2008, 16:73-80.

14. Beal MW: Women's use of alternative and complementary therapies in reproductive health care. J Nurse Midwifery 1998, 43:224-34.

15. Katz Michael: Aquamarine Water: Fountain of Youthful Vitality. In Drinking Aquamarine Water Volume Chapter 2. First edition. Gemisphere, Portland; 2002.

16. Patel KP: Healing power of Hessonite (Crystal) on Human Breast Cancer Cells. [http://www.acsu.buffalo.edu/ kppatel/].

17. Riddle JM: History as a tool in identifying 'new' old drugs. Adv Exp Med Biol 2002, 505:89-94.

18. Jain VK: The Science of Gemstone Therapy. [http://www.self growth.com/articles/The Science of Gemstone Therapy.html].

19. Electronic Gem Therapy [http://www.btinternet.com/ f.willen brock/fr $\mid 2 . h t m]$

20. Katz Michael: Gemstone Energy Medicine: Healing Body, Mind and Spirit. In A Vision of Gemstone Energy Medicine Volume chapter 6. First edition. Natural Healing Press, Portland; 2005:359-66.

21. Shaikh Babar T, Hatcher Juanita: Complementary and Alternative Medicine in Pakistan: Prospects and Limitations. Evid Based Complement Alternat Med 2005, 2: I39-142.

22. Secor ER, Markow MJ, Mackenzie J, Thrall RS: Implementation of outcome measures in a complementary and alternative medicine clinic evidence of decreased pain and improved quality of life. J Altern Complement Med 2004, I 0:506-I3.

23. World Medical Association Declaration of Helsinki, Ethical Principles for Medical Research involving human subjects [http://www.wma.net/e/policy/b3.htm]

24. Cincotta DR, Crawford NW, Lim A, Cranswick NE, Skull S, South M, Powell CV: Comparison of complementary and alternative medicine use: reasons and motivations between two tertiary children's hospitals. Arch Dis Child 2006, 91:153-8.

\section{Pre-publication history}

The pre-publication history for this paper can be accessed here:

http://www.biomedcentral.com/1472-6882/9/32/prepub

Publish with Bio Med Central and every scientist can read your work free of charge

"BioMed Central will be the most significant development for disseminating the results of biomedical research in our lifetime. "

Sir Paul Nurse, Cancer Research UK

Your research papers will be:

- available free of charge to the entire biomedical community

- peer reviewed and published immediately upon acceptance

- cited in PubMed and archived on PubMed Central

- yours - you keep the copyright 